\title{
Loose change is not enough
}

\author{
The financial sector relies on climate risk assessments that overlook uncertainties. COP26 provides a platform for \\ regulators to agree on acceptable risk tolerances, as the science of asset climate risk matures.
}

( ne of the most contentious items of discussion at the 26th Conference of the Parties (COP26) meeting in Glasgow in November 2021 will probably be the regulation of financial flows to mitigate climate change risk and direct investment towards renewable energy technologies ${ }^{1}$. As money managers decide which investments are bound to be most profitable and which ones are the riskiest - thereby determining what types of energy projects advance and what infrastructure gets built - financial regulations will also be one of the most important issues to tackle at COP26.

The financial sector is not going into COP26 with a blank slate. There are three main lenses through which the financial sector looks at climate change: environmental, social and governance (ESG) ratings and rankings for companies, climate risk assessments and the design of funds investing in companies with high ESG scores. In the last couple of years, in particular, there has been an impetus on setting net-zero targets that initiate at the fund and investor level and percolate down to individual companies.

ESG metrics include indicators from pollutant emissions to management structure for handling ESG issues. A single industry standard ESG rating or ranking system has yet to emerge, though there is significant overlap between ratings offered by many commercial providers in terms of themes and indicators. ESG funds are designed to include investments with high ESG scores, but how these funds perform in comparison to the market and whether ESG ranking offers any competitive advantage is a question of continued research and contention.

Climate risk assessments within the financial sector similarly have yet to converge on a single industry standard, though there is thematic and conceptual overlap between various commercial risk ranking providers. The risk is generally split between physical and transitional risk. Regulatory risk is also considered separately from transitional risk by some providers because of its significance in particular for the conventional energy sector. Physical risk estimates look at increasing the probability of various natural hazards spatially and map them onto the physical assets of the company being assessed. Transitional risk estimates look at regulatory risk such as stringent climate policies kicking in to increase the cost of business for some sectors, as well as technology obsolescence and other such risks. There is currently significant subjectivity built into the assessment of these risks.

While ESG scoring and climate risk-assessment tools in the financial industry have evolved considerably over the years, achieving some sophistication in their design and implementation, their scientific bases remain less than clear. Major ESG scoring systems for instance have proprietary elements that have not undergone scientific peer review. The effectiveness of any of the ESG scoring systems and disclosure in reducing carbon emissions or mitigating exploitative labour conditions or in achieving any of their stated goals is yet to be established scientifically ${ }^{2}$. What's worse is that there continues to be disagreement about the impact of ESG scores on the financial performance of investments. High ESG scores are neither a guarantee of environmental action nor a predictor of short- or long-term return on investment.

Climate risk-assessment tools and metrics similarly suffer from a lack of grounding in scientific peer review. Many climate risk-assessment tools estimate physical risk at the asset or facility level. This requires arriving at statistical probabilities of, say, weather events or earthquakes striking at specific power plants and then estimating how these probabilities will evolve due to climate change. This is not possible to do accurately with any degree of reasonable scientific certainty ${ }^{3}$. Yet the models estimate physical risks and arrive at numbers that are then used to estimate value-at-risk for assets, companies and portfolios.

Similar uncertainties in estimation of technological transition risks and regulatory risks are glossed over in favour of arriving at some quantitative estimation of risks. Such estimates can theoretically be useful as a means of comparing two companies or assets but the empirical scientific basis to justify such a comparison is also not available in peer-reviewed work.

Another problem is that climate risks are composite and events like the bankruptcy of the utility PG\&E in California after being held liable for third-party losses, and the resulting blackouts in the state the following year, are born of failures cascading across multiple systems. Natural disasters give birth to infrastructure failures that lead to legal and financial disruptions. Such composite failures are the primary threat that climate change poses, yet scientifically, such composite risks are near impossible to model and predict.

What the rough and ready indicators and metrics used by the financial industry show is the thirst for immediate actionable information. In many cases, peer-reviewed climate and energy systems modelling science is not able to provide this information credibly with any level of certainty.

Since the science isn't there yet, the financial industry has developed their own metrics for climate risk, essentially grading their own homework. The metrics are prone to bias and open to interpretation, leading so far to ambitious claims not being backed by any real change on the ground. For example, the flow of capital in the direction of renewable energy as opposed to fossil fuels is still less than $40 \%$ (ref. $^{4}$ ).

This is a problem that can only be solved by supra-scientific consensus bodies like the Intergovernmental Panel on Climate Change. As pointed out in a Q\&A in this issue, policymakers want more clarity from science but need to understand that immediate action must to be taken based on the clarity already there. The participants at COP26 would do well to come up with stringent climate risk tolerances for energy investors. These risk bounds need to be well-defined enough to not leave any loopholes and comprehensive enough to affect change at the global level. Irrespective of the extent to which progress is made towards this goal at COP26, estimating such risk envelopes with increasing certainty could form a very useful research agenda going forward, informing policy makers at high level fora like future COPs.

Published online: 20 October 2021 https://doi.org/10.1038/s41560-021-00928-0

References

1. Carney, M. Building a Private Finance System for Net Zero: Priorities for Private Finance for COP26 (UN COP, 2021); https://ukcop26.org/wp-content/uploads/2020/11/COP 26-Private-Finance-Hub-Strategy_Nov-2020v4.1.pdf

2. Ameli, N., Kothari, S. \& Grubb, M. Nat. Clim. Change https://doi.org/10.1038/s41558-021-01174-8 (2021).

3. Grieve, C. Top scientist says APRA climate risk guidance 'flawed'. The Sydney Morning Herald (30 August 2021); https://www.smh. com.au/business/banking-and-finance/top-scientist-says-apraclimate-risk-guidance-flawed-20210820-p58khr.html

4. World Energy Investment 2020: Key Findings (IEA, 2020); https:// www.iea.org/reports/world-energy-investment-2020/key-findings 